\title{
Impactos das relações Banco Central x Bancos Estaduais no arranjo federativo pós-1994: Análise à luz do caso Banespa ${ }^{\mathrm{x}}$
}

\author{
Impacts of relations between Central Bank and State \\ Banks in the post-1994 federative arrangement: \\ Analysis in the light of the Banespa case
}

\author{
CHRISTOPHER GARMAN* \\ CRISTIANE KERCHES DA SILVA LEITE** \\ MOISÉS DA SILVA MARQUES***
}

RESUMO: Este artigo indica, por meio do estudo de caso do processo de federalização do Banespa, que deve haver sérias reservas quanto à ideia atual de que houve centralização do poder no governo central imposta pelo executivo federal nos anos 90 . O caso Banespa é um estudo de caso crítico, pois demonstra que a reestruturação do sistema bancário estadual não é causada pelo governo federal em nome da manutenção do processo de estabilização econômica. Os autores argumentam que o acordo envolvendo a situação dos bancos estaduais foi fruto de uma negociação política entre o governo estadual e o governo federal. Assim, a atual reestruturação do sistema federativo pode ser melhor explicada por um processo de negociação entre os ramos do governo do que pela reestruturação imposta pelas pessoas maior escalão.

PALAVRAS-CHAVE: Banco central; federalism; centralização; sistema bancário.

ABSTRACT: This article indicates, through the case study of the Banespa federalization process, that there should be serious reservations concerning the current idea that there was centralization of power in the central government enforced by the federal executive in the

\footnotetext{
x Agradecemos e procuramos incorporar, na medida do possível, os comentários de Lourdes Sola, Eduardo Kugelmas, Maria Rita Loureiro, Fernando Abrucio, Cláudio Couto, Brasílio Sallum Jr. e Wagner Iglecias, além de dois pareceristas anônimos da Revista de Economia Política, isentando-lhes, obviamente, de quaisquer responsabilidades sobre erros que porventura permaneçam.

* Doutorando em Ciência Política da Universidade de San Diego, San Diego, Califórnia, Estados Unidos. E-mail: garman@eurasiagroup.net.

* Mestranda em Ciência Política e Economista pela Faculdade de Economia e Administração da Universidade de São Paulo - FEA/USP, São Paulo/SP, Brasil. E-mail: criskerches@gmail.com

*** Professor do Curso de Relações Internacionais da Faculdade Santa Marcelina - FASM, São Paulo/ SP, Brasil. E-mail: moises.marques@fasm.edu.br
} 
1990's. The Banespa case is a critical case study as it demonstrates that the restructuring of the state banking system is not caused by federal government in the name of the maintenance of economic stabilization process. The authors argue that the agreement involving the situation of state banks was the fruit of a political bargaining between the state government and the federal government. Thus, the current restructuring of federative system can be better explained by a bargaining process between the branches of the government than by the restructuring enforced by the top people.

KEYWORDS: Central bank; federalism; centralization; bank system.

JEL Classification: G21; E58; G34.

\section{INTRODUÇÃO: O PROBLEMA EM PERSPECTIVA}

O sistema federativo brasileiro é freqüentemente caracterizado como uma contínua alternância no balanço de poder entre a esfera federal e a esfera dos governos subnacionais. Historicamente, sistemas políticos extremamente descentralizados na esfera estadual se revezaram com sistemas nos quais o poder político é centralizado no governo fe deral. ${ }^{1}$ Com o advento do Plano Real, existe uma idéia corrente, principalmente nos editoriais da imprensa e mesmo em publicações de cunho acadêmico, de que o balanço de poder entre os níveis de governo novamente está se movimentando em direção ao governo federal, ${ }^{2}$ por imposição unilateral deste. Como ocorreu durante a década de 80 e o início da década de 90 , o governo federal tem refinanciado as dívidas estaduais. No entanto, o round recente de negociações contém duas ressalvas importantes: a privatização de grande parte das empresas pertencentes aos estados e novas restrições sobre operações de crédito estadual. A habilidade do governo central para impor essas duas condições sobre o recente refinanciamento das dívidas estaduais é vista como evidência de que está havendo uma centralização de poder no governo federal imposta unilateralmente por parte deste.

Através do estudo de caso da privatização do Banespa, porém, nosso trabalho indica sérias ressalvas à idéia corrente de que houve uma centralização de poder no governo central imposta pelo executivo federal. Enquanto o recente round de negociações entre o governo central e estadual difere das negociações encaminhadas

\footnotetext{
1 Sistemas com poderes políticos extremamente descentralizados na esfera estadual foram verificados durante a Primeira República (1891-1930), o regime democrático vigente de 1946 a 1964 e a democracia atual. Por sua vez, sistemas nos quais o poder político era centralizado no governo federal se deram no Império, na "era" Vargas (1930-1946) e durante o regime militar.

${ }^{2}$ Em Abrucio (1998), relacionam-se alguns fatores que favoreceram a União no processo de redistribuição de poder político no período marcado pelo advento do Plano Real: “(... ) aumento do poderio financeiro da União, da legitimidade presidencial junto à opinião pública(...), a vitória de governadores aliados nos principais estados (nas eleições casadas de 1994), e a construção de uma coalizão baseada em uma agenda inicial bastante consensual entre os componentes da base governista, ressaltaram os aspectos majoritários do sistema político, beneficiando o Governo Federal (além da crise financeira e administrativa dos estados)". (Abrucio 1998: 228)
} 
durante a década de 80 e início da década de 90, pela gravidade da crise fiscal dos estados e a reforçada posição política do presidente Fernando Henrique Cardoes no Congresso, nós argumentamos que a atual reformulação do sistema federativo se deve muito mais a um processo de barganha entre as esferas de governo do que uma reformulação imposta "por cima".

A crise fiscal dos estados e a reestruturação no sistema financeiro estadual engloba uma grande diversidade de temas e referências analíticas. Nosso estudo se restringe ao caso Banespa e oferece algumas vantagens. Primeiro, a recente transformação do setor financeiro público estadual encaminhada pelo governo federal, e em particular pelo Banco Central do Brasil, tem grandes possibilidades de mudar a balança de poder entre as esferas de governo. Como vários analistas já demonstraram, os bancos comerciais estaduais ampliaram consideravelmente a autonomia fiscal dos seus respectivos governos estaduais, através de uma diversidade de mecanismos durante as décadas de 80 e início dos $90 .{ }^{3}$ A recente onda de privatização de grande parte dos bancos estaduais pode estar apontando para um novo regime fiscal no nível estadual. A segunda razão para tal recorte decorre da primeira. Exatamente porque a recente transformação do setor tem implicações tão significativas para a autonomia fiscal entre os níveis de governo, o processo foi altamente politizado - criando uma área fértil de pesquisa para um estudo sobre as relações federativas envolvendo atores como os próprios governadores, $\mathrm{o}$ Executivo Federal e os legisladores federais (tanto deputados como senadores), além do próprio Judiciário.

Optamos por realizar um estudo do caso Banespa porque se trata de um criticai case study. A priori, tratava-se do maior banco estadual do sistema bancário nacional; logo, qualquer problema financeiro neste banco deveria repercutir fortemente em todo o sistema. Pelo mesmo motivo, o caso Banespa é exemplar devido ao fato de sua negociação ter se tornado, de certa forma, um modelo para as negociações dos bancos dos outros estados. Essencialmente, o caso Banespa é paradigmático, pois demonstra que a reestruturação do sistema bancário estatal não reflete uma imposição unilateral do Governo Federal em nome da sustentabilidade do processo de estabilização econômica. Ao nosso ver, o acordo oriundo do desenlace da questão dos bancos estaduais foi fruto de um jogo de barganha política entre os governos estaduais e o governo federal. Os termos da barganha entre os atores políticos serão apresentados no decorrer do trabalho.

Este trabalho está dividido em quatro seções. A primeira esboça o pano de fundo do estudo sobre o caso Banespa. A segunda refere-se às mudanças propriamente ditas, na relação BACEN x bancos estaduais, no período pós-1994, enquanto a terceira é dedicada a um balanço das principais hipóteses para explicar tais

\footnotetext{
3 Os principais mecanismos para ampliar a autonomia fiscal dos governos estaduais, usando as instituições financeiras, foram: empréstimos diretos para o governo estadual, empréstimos às empresas estatais e a responsabilidade de carregar suas carteiras com títulos estaduais, assumindo o risco do mercado privado não aceitá-los.
} 
mudanças. A seguir, como cerne deste artigo, é feita uma abordagem do caso Banespa, com a perspectiva de encontrar valiosos insights que devem nortear as considerações finais. À guisa de conclusão resgatamos os principais pontos suscitados na análise, propondo algumas respostas às questões anteriormente abordadas.

\section{O “CHOQUE” DE 94: CRISE FISCAL, FATORES INTERNACIONAIS E MUDANÇA NO REGIME INFLACIONÁRIO}

Com o advento do Plano Real, temos observado uma série de mudanças no regime fiscal dos estados e, o que nos interessa neste momento, mudanças importantes no sistema financeiro estadual. $O$ contexto deste processo de reestruturação das instituições bancárias estaduais, que é um dos capítulos de um processo mais amplo de reformulação do sistema financeiro nacional, é constituído de fatores de ordem doméstica e internacional. Os fatores de ordem doméstica referem-se à mudança do regime inflacionário ensejada com o Plano Real e a decorrente crise fiscal dos estados. Os fatores de ordem internacional relacionam-se com a crescente pressão internacional na direção do saneamento dos sistemas bancários nacionais (públicos e privados). Estes fatores serão abordados nesta seção, com o intuito de se formar um pano de fundo para o estudo do caso Banespa.

Para entender o impacto da mudança do regime inflacionário, com o advento do Plano Real, é preciso abordar rapidamente a relação entre o processo inflacionário brasileiro e o sistema bancário público, ${ }^{4}$ assim como a relação entre o Banco Central e as instituições financeiras, anteriormente ao Plano Real. Por definição, o BACEN deveria ter o controle da base monetária no país. No entanto, historicamente isso não vinha ocorrendo, uma vez que a autoridade monetária foi estendendo o "privilégio de convertibilidade" (zeragem automática) a uma gama cada vez mais ampla de ativos financeiros mantidos pelo público e pelos governos. Ademais, através da rede de bancos oficiais federais e estaduais, a convertibilidade foi também garantida aos títulos públicos estaduais e aos títulos de emissão própria destes bancos. A maioria dos títulos nos bancos públicos estaduais dizia respeito a dívidas de seus controladores (os estados), apesar dessa prática estar sensivelmente limitada desde a vigência da Lei ${ }^{\circ}$ 4.595/64, criadora do Sistema Financeiro Nacional. Todas as legislações no sentido de manter um controle sobre o nível de endividamento dos estados com suas instituições financeiras foram sistematicamente burladas, entre as décadas de 70 e 80 . Ao perceber o agravamento do problema, o BACEN tentou implementar programas de recuperação para esses bancos públicos, como o PAC - Programa de Apoio Creditício e o PROREF — Programa de Recuperação Econômico-Financeira; entretanto, embora diversas instituições tenham utilizado recursos ou vantagens desses programas, muito poucas fizeram a "lição

\footnotetext{
4 Uma análise da relação entre estes dois fatores não vai ser tratado pormenorizadamente aqui, pois isso já foi feito de forma pertinente em vários outros trabalhos. Veja Martone (1994).
} 
de casa". Ainda com a mesma preocupação, o Banco Central instituiu em 25.02.87, através do Decreto-Lei n ${ }^{\circ}$ 2.321, o RAET - Regime de Administração Especial Temporária, que passou a permitir a intervenção direta da autoridade monetária nas instituições problemáticas e, em última instância, a liquidação extrajudicial das mesmas. Embora o Banco Central tenha lançado mão da prerrogativa do RAET em vários momentos, os bancos estaduais sob intervenção sempre foram devolvidos aos seus respectivos controladores, devido a pressões políticas.

Foi somente na metade da década de 90 que a autoridade monetária conseguiu exercer uma autoridade efetiva vis-à-vis aos agentes e instituições financeiras, a partir da conjunção dos três fatores ambientais que já citamos acima: a crise fiscal dos estados; as mudanças no panorama internacional e o Plano Real.

No marco legal pós-Constituinte de 1988, o nível de governo subnacional obteve acesso a um conjunto de recursos financeiros, administrativos e políticos que representou poderoso instrumento para o Executivo dos estados tornar-se capaz de cooptar a classe política estadual, lançando mão de recursos de patronagem como fonte de poder. Segundo Abrucio (1998), esta renovação das formas de cooptação política dos governadores no sistema político brasileiro data das eleições de 1982 para governadores estaduais - coincidentemente ou não, este período também marca o início do processo de deterioração da performance dos bancos estaduais, diagnosticado pelo Banco Central. Esse modelo de administração pública marcado pelo acesso a mecanismos de criação de receitas inconsistente intertemporalmente e de total liberdade de expansão das despesas, no nível estadual, perdurou intacto até o momento da implementação do Plano Real.

Grosso modo, segundo Abrucio (1998), os estados perderam boa parte de seus instrumentos de "fabricar receita" orçamentária ao serem alijados dos ganhos financeiros advindos da inflação e da capacidade de usar indiscriminadamente os recursos oriundos dos bancos estaduais. Neste contexto, o agravamento de uma crise financeira dos estados gestada historicamente foi inevitável.

Com relação ao segundo fator, nos últimos anos, a história econômica mundial vem registrando mudanças cruciais no mercado mundial de capitais, que invariavelmente extrapolam a lógica de funcionamento das economias nacionais stricto sensu. Com relação às economias emergentes, observa-se um impressionante fluxo de capitais atraídos pela alta rentabilidade, a despeito dos riscos implícitos a estas economias recém-abertas e desregulamentadas, em virtude das pressões exercidas nos últimos tempos pelos organismos financeiros internacionais. O quadro de desequilíbrio macroeconômico crônico vigente impõe a internalização de um princípio de cautela e salvaguarda ao discurso dos órgãos financeiros internacionais. $\mathrm{O}$ FMI, ao liderar programas de assistência internacional, estabeleceu que os países assistidos deveriam oferecer como contrapartida o compromisso de implementar reformas econômicas saneadoras, incluindo reformas no sistema financeiro e na área fiscal. De fato, com essas mudanças e a partir da vigência do próprio Acordo

\footnotetext{
${ }^{5}$ Para uma análise política da intervenção dos bancos estaduais, ver Paes (1996) e Sola (1995).
} 
da Basiléia ${ }^{6}$, caminha-se a passos largos para o estabelecimento de um padrão internacional de solvência para os bancos em todo o mundo, o que restringiria fortemente os arranjos particulares dos sistemas financeiros de cada país e, especialmente, o espaço de manobra da ação de cada Banco Central. Pode-se afirmar, com certeza, que existe uma demanda visivelmente crescente de uma ação coordenada dos bancos centrais em torno da proteção das moedas nacionais, vis-à-vis o elevado grau de transnacionalização das economias mundiais.

Finalmente, o efeito da queda brutal dos patamares inflacionários, após o Plano Real, refletiu-se invariavelmente no sistema bancário. Os bancos tinham suas receitas infladas pelo chamado floating ${ }^{7}$ bancário. Pode-se notar na Tabela 1 a queda da participação das instituições financeiras no produto interno bruto, uma vez que dos cerca de $15 \%$ que representavam em 1993, já, em 1996, possuíam apenas $4,7 \%$ do quinhão.

\begin{tabular}{cc}
\hline \multicolumn{2}{c}{ Tabela 1: Participação do Sistema Financeiro no PIB } \\
\hline Ano & $\%$ do PIB \\
\hline 1990 & 12,78 \\
1991 & 10,53 \\
1992 & 12,13 \\
1993 & 15,61 \\
1994 & 12,37 \\
1995 & 6,94 \\
1996 & 4,7 \\
\hline
\end{tabular}

A necessidade de ajuste das instituições financeiras, principalmente as públicas, que já era premente desde a mudança das condições financeiras internacionais, passou a ser extremamente visível. Esse ajuste, de acordo com Mendonça de Barros e Almeida Jr. (1997), passa por três fases: 1) diminuição do número de bancos, em decorrência da liquidação, incorporação, fusão e transferência de controle acionário; 2) entrada de bancos estrangeiros no mercado nacional e início dos ajustes do sistema financeiro público e 3) profunda modificação no modelo operacional dos bancos. Essas fases estão acontecendo simultaneamente, desde o segundo semestre de 1994 (início da vigência do Plano Real). Tudo isso levou, de certa forma, a uma recentralização de poder nas mãos do BACEN, ratificada pelo número de intervenções do órgão, entre 94 e 97, conforme Tabela 2.

\footnotetext{
${ }^{6}$ Para maiores detalhes das normas estabelecidas pelo Acordo da Basiléia, ver Fortuna (1995).

${ }^{7}$ Esse ganho era proporcionado pela perda do valor real dos chamados depósitos à vista e, muitas vezes, pela correção dos depósitos bancários abaixo dos índices inflacionários. No jornal Gazeta Mercantil de 14.05.97, estimou-se que os bancos públicos perderam cerca de $\mathrm{R} \$ 12$ bilhões dos $\mathrm{R} \$ 19$ bilhões da receita inflacionária; portanto, foram os grandes perdedores com o processo de estabilização.
} 
Tabela 2: Atuação do Banco Central sobre

o Sistema Bancário (Julho/1994 a Dezembro/1997)

\begin{tabular}{lc}
\hline \multicolumn{1}{c}{ Tipo de Instituição } & $\begin{array}{c}\text { Número de liquidadas, } \\
\text { sob intervenção ou RAET }\end{array}$ \\
\hline Banco de Investimento & 1 \\
Banco Comercial Privado Nacional & 4 \\
Banco Comercial Público Estadual & 3 \\
Banco de Desenvolvimento Estadual & 1 \\
Banco Múlt. Nac. c/ Part. Estrangeira & 2 \\
Banco Múltiplo Privado Nacional & 28 \\
Banco Múltiplo Público Estadual & 4 \\
\hline TOTAL & 43 \\
\hline
\end{tabular}

Fonte: Banco Central do Brasil

\section{MUDANÇAS NA RELAÇÃO BANCO CENTRAL X BANCOS ESTADUAIS - O PÓS-1994}

Os fatores ambientais citados na seção anterior exigiram, como contrapartida, alterações substanciais no Sistema Financeiro Nacional. No que tange ao bancos estaduais, as mudanças começaram no final do ano de 1994. Em 30 de dezembro o Banespa e o Barrerj, dois dos maiores bancos estaduais do país, sofreram intervenção. A seguir, foi a vez do Banco do Estado de Alagoas (23.01), Banco do Estado de Mato Grosso (06.02) e Banco do Estado de Rondônia (20.02). Na verdade, a situação de insolvência desses bancos já era sobejamente conhecida pelos gestores da política econômica, uma vez que não dava para continuar fazendo uma política econômica de estabilização para organizar esse sistema e torná-lo mais eficiente sem que fossem tomadas medidas como o PROER, o saneamento/capitalização dos bancos federais e o PROES. Ademais, a situação ficava ainda mais explícita, nas palavras de Paolo Zaghen ${ }^{8}$, “... exatamente numa época em que as finanças dos estados também estavam absolutamente deterioradas".

Em agosto de 1996 entrou em vigência a Medida Provisória no 1.514, que redundou na criação do PROES - Programa de Incentivo à Redução do Setor Público Estadual na Atividade Bancária. Por esse novo programa, a União concordava em refinanciar as dívidas dos estados com seus respectivos bancos em troca

\footnotetext{
${ }^{8}$ Entrevista concedida a Christopher Garman e Moisés Marques.
} 
de algumas medidas. Havia duas opções: a) o financiamento do total dos débitos levava necessariamente à privatização, extinção ou transformação em agências de fomento e b) o financiamento de $50 \%$ dos débitos mantinha o banco nas mãos dos controladores (estados), mas requeria como contrapartida o enxugamento dos mesmos, além de critérios de administração e concessão de créditos mais transparentes.

A ação mais eficaz do BACEN, no período pós-94, sobre os bancos públicos, pode ser verificada numa rápida análise de seus Indicadores Econômico-Financeiros. Tomando-se como base os indicadores dos bancos privados, a grande maioria das demonstrações financeiras dos bancos públicos, a partir de 1995, demonstra a melhoria no item liquidez corrente (que indica um maior "casamento" de prazos entre captações e aplicações, na medida em que mais se aproxima de 1,00); notase, também, o aparecimento, nos exercícios de 95 e 96, de vários prejuízos como resultados líquidos dos bancos públicos, o que reflete uma política de provisionamenta de créditos de liquidação duvidosa, observada, a partir de então, em função do maior rigor do agente fiscalizador. Nota-se ainda a diminuição das despesas de pessoal em relação ao ativo total, aproximando-se dos indicadores dos bancos privados, reflexo dos planos de demissão voluntária, levados a cabo, muitas vezes, por sugestão do próprio BACEN e, finalmente, também a diminuição do percentual das operações de crédito com o setor público (mormente os governos estaduais), reflexo da vigência, desde a segunda metade dos anos 80 , da proibição de novos empréstimos aos controladores e, já nas demonstrações financeiras de 97, da renegociação das dívidas dos estados. Deve-se ressaltar que, o maior problema desses bancos, na verdade, era fiscal, na medida em que grande parte de seus ativos eram dívidas dos estados ou de empresas estatais, considerados impagáveis. ${ }^{9}$

As intervenções revelaram diversos tipos de outros problemas nesses bancos, tais como: a) aumento das despesas administrativas pela ausência de rotatividade funcional; b) dificuldades em acompanhar o desenvolvimento tecnológico das outras instituições (por excesso de burocracia legal); c) ingerências políticas; d) análise de crédito que não seguia as boas normas bancárias; e) empréstimos concedidos com critérios políticos e, f) estrutura de ativos em que tinham maior peso os empréstimos dados ao controlador, considerados non performing, o maior problema dessas instituições. Ainda de acordo com Zaghen, esse processo só se deu porque “... o Plano Real criou as condições econômicas... para que o problema ficasse explicitado e o governo Fernando Henrique reuniu as condições políticas para que se pudessem tomar atitudes que resolvessem esse problema”.

Em resumo, na Tabela 3 podemos notar a situação dos bancos estaduais, no início de 1999, fruto das medidas adotadas pelo BACEN. Das 33 instituições existentes (nem todas elas em plena operação), apenas quatro ainda não optaram por um ajuste totalmente rigoroso, notadamente naqueles estados em que não havia

\footnotetext{
${ }^{9}$ Para Mendonça de Barros, Loyola e Bogdanski (1998) "na verdade, o problema dos bancos estaduais tem origem de natureza muito mais fiscal do que propriamente bancária, mas as suas dimensões não permitem outro tipo de solução”. (p. 10)
} 
(até 1998) condições políticas para acordo nas Assembléias Legislativas (ES e DF) ou em bancos sem atrativos para a privatização.

Tabela 3: Situação dos Bancos Públicos Estaduais em Outubro/2000

\begin{tabular}{|c|c|c|}
\hline Privatizados & 6 & $\begin{array}{l}\text { (Banerj/RJ, Credireal e Bemge/MG, Bandepe/PE, } \\
\text { Baneb/BA e Banestado/PR) }\end{array}$ \\
\hline Privatização/Federalização & 7 & (SP, RO, CE, MA, GO, AM e SC) \\
\hline Saneamento & 6 & (RS, SE, SP, PA, ES e MG) \\
\hline Liquidação Extrajudicial & 3 & $(A L, A P$ e $R N)$ \\
\hline Não optantes & 4 & (ES, PI, PB e DF) \\
\hline Extinção & 7 & (SC, MG, MT, AC, RR, BA e RS) \\
\hline TOTAL & 33 & \\
\hline
\end{tabular}

Fonte: Banco Central do Brasil

Do montante envolvido no ajuste dos bancos estaduais, explicitado na Tabela 4, os bancos de São Paulo - Banespa e Nossa Caixa, de acordo com valores contratados, respondiam por cerca de $60 \%$ dos recursos (em razão do montante da dívida do estado/empresas estatais para com esses bancos), sendo que a dívida foi refinanciada para os estados, em 30 anos, à taxa de IGP + 6\% a.a. Cabe lembrar que, no caso do ajuste dos bancos públicos estaduais e mormente do PROES, não há uma injeção de moeda no sentido literal, mas sim uma troca de dívidas, sendo que o Governo Federal passou a ser credor do Governo Estadual, colocando, para tanto, títulos públicos federais nos ativos dos respectivos bancos estaduais, em lugar de créditos anteriormente considerados impagáveis. No entanto, pelo acordo citado acima, os estados passaram a ter obrigações com a União, que devem ser honradas, caso contrário podem perder o direito ao repasse de verbas constitucionalmente vinculadas.

Tabela 4: Montante do Ajuste dos Bancos Estaduais — Valor Contratual (R\$ bilhões)

\begin{tabular}{lcllll}
\hline Banespa & 24 & Baneb & 0,9 & Badesc & 0,2 \\
Nossa Caixa & 5,6 & Banrisul & 0,6 & Banestes & 0,2 \\
Banerj & 3,9 & Beron & 0,5 & Besc & 0,1 \\
Banestado & 3,9 & Desenbanco & 0,4 & Banacre & 0,1 \\
Bemge & 1,6 & Produban & 0,4 & Badern & 0,1 \\
Minas Caixa & 1,4 & BEG & 0,4 & Banpara & 0,1 \\
CEERGS & 1,4 & BEA & 0,4 & Baner & 0 \\
Bandepe & 1,3 & Credireal & 0,4 & Banese & 0 \\
BDMG & 1,1 & Bemat & 0,3 & Banap & 0 \\
BEC & 1 & BEM & 0,3 & BEP & 0 \\
\hline
\end{tabular}

Fonte: Banco Central do Brasil

Todo esse processo teve como parâmetros de indução não somente a racionalidade econômica, mas também negociações políticas, que influenciaram na con- 
formação final. Os efeitos, ainda que seja prematuro dá-los como findos, apontam para algumas tendências no que tange ao desenho federativo. É por isso, que analisaremos adiante o caso do Banespa, para verificar a acuidade das hipóteses de trabalho e apontar alguns insights que nos auxiliem a delinear tendências.

\section{LEVANTAMENTO DE HIPÓTESES E QUESTÕES}

Até este momento, reunimos elementos que permitem conceber o outcome do processo, qual seja, a mudança na relação entre o Banco Central e as instituições financeiras estaduais. Contudo, a percepção dos fatores condicionantes da dimensão causal da mudança não basta para esgotar as possibilidades analíticas do objeto em questão. De fato, até o momento, constatamos que há muito a ser abordado. Algumas questões podem ser formuladas. Considerando a hipótese de que o outcome envolveu um processo de barganha entre os atores políticos estratégicos, como o acordo foi viabilizado? Se houve um processo de redistribuição do poder federativo, este foi fruto de uma estratégia de imposição do governo federal? Se for o caso, quais são as fontes de poder que legitimam tal estratégia de ação do Executivo Federal?

Por outro lado, como podemos qualificar a consistência política do fato econômico em jogo - o ajuste do sistema bancário? Trata-se de um processo que tende a imprimir uma mudança estrutural inexorável no padrão de relação entre o BACEN e as instituições bancárias? Com o fato econômico do ajuste, temos um processo de recentralização do poder nas mãos do Executivo?

Nossa hipótese forte é que o outcome, fruto de um conjunto de causas multifacetadas - a crise fiscal, o panorama internacional, o Plano Real -, reflete essencialmente uma negociação política entre atores localizados em diferentes níveis de governo, não sendo fruto, deste modo, somente dos impactos dos fatores ambientais. Nesta perspectiva, constatando-se que ainda há muito a ser explicado, propomos a análise do caso Banespa, como fonte primordial de insights, especialmente no que tange à investigação dos impactos políticos do processo e à consistência política do fato econômico - as interfaces políticas do processo de ajuste do sistema de bancos estaduais.

\section{BANESPA: UM ESTUDO DE CASO RELEVANTE}

\section{Por que o Banespa?}

As seções prévias demonstraram concisamente a extensão pela qual periódicas crises do sistema bancário e as respostas subseqüentes do Banco Central, são inseparáveis das relações políticas existentes entre os níveis federal e estadual de governo. A força política dos governadores, durante os anos 80, impediu que o Banco Central impusesse sanções significativas aos estados, após intermitentes socorros 
financeiros da autoridade monetária aos bancos estaduais. A recente crise dos bancos estaduais, entretanto, tem rompido com essa tendência anterior ao condicionar o socorro financeiro dos bancos estaduais a uma eventual privatização ou transformação em banco de desenvolvimento ou agência de fomento.

A resposta corrente do Banco Central reflete a robustez da política econômica através da eliminação de um sério problema de "risco moral" no sistema financeiro do país, especialmente a partir da segunda metade de década de 90 . Neste caso, risco moral, ou moral hazard, descreve uma situação na qual cada agente financeiro tem incentivos para agir de forma irresponsável — no caso, tornar-se insolvente -, porque tem a consciência de que o socorro da autoridade monetária central será líquido e certo. Contudo, algumas outras questões permanecem sem resposta. Primeiro, quais fatores políticos permitiram que o governo federal impusesse uma solução para o setor, impensável durante os anos 80 e os primeiros anos da década de 90 ? A recente resposta à crise do sistema bancário reflete uma mudança no peso relativo do poder político do governo federal, ou reflete mais um compromisso entre governos estaduais e federal — assim indicando a precipitação em afirmar a idéia corrente da "recentralização"?

Através de um estudo de caso do Banespa, nós argumentamos que a corrente reestruturação do setor bancário estatal, de fato reflete uma crescente centralização do poder político nas mãos do governo federal - ainda com sérias qualificações a serem feitas à interpretação da "recentralização".

O presente estudo de caso é capaz de demonstrar claramente as negociações políticas culminantes na formulação do programa PROES devido, em larga medida, ao fato de que o programa foi criado como uma conseqüência das negociações em torno de uma solução para a crise financeira do Banespa. Por um lado, isso deriva do fato de que o banco era o maior do setor no país, representando aproximadamente 40\% (em termos de Património Líquido em 1993), fazendo com que qualquer programa para reestruturar o setor tivesse de garantir a restauração do equilíbrio financeiro do banco. Por outro lado, essa visibilidade do caso Banespa também deriva das negociações políticas com o Senado para aprovar o protocolo assinado pelos governos federal e estadual de São Paulo sobre o acordo. Senadores dos estados das regiões Norte e Nordeste somente concordaram em refinanciar a dívida do estado de São Paulo com o Banespa na condição de o governo federal prover linhas similares de financiamento aos seus estados. Em suma, o estudo de caso do Banespa, ao nosso ver, fornece importantes insights no entendimento das negociações políticas com o setor bancário estadual não somente devido ao tamanho do banco - vis-à-vis os demais bancos estaduais-, mas devido, essencialmente, às negociações envolvendo as intervenções bancárias que precederam a criação do PROES.

Esta seção pretende examinar três estágios nas negociações em torno da insolvência do Banespa. Em primeiro lugar, nós examinamos a decisão do Banco Central de declarar a intervenção do Banespa e do Banerj em 30 de dezembro de 1994 (um dia útil antes da posse dos governadores eleitos naquele ano), e argumentamos que o timing de tal intervenção foi conduzido primordialmente por uma lógica política. 
Em segundo lugar, nós examinamos as negociações orientadas pelo protocolo das intenções assinado por São Paulo e pelo governo federal em janeiro de 1996, e sua subseqüente tramitação na Assembléia Legislativa do estado e no Senado Federal. Em terceiro lugar, nós examinamos as razões pelas quais o protocolo foi abandonado e houve a segunda rodada de negociações, que incluiu a dívida do Banespa em um conjunto mais amplo de negociações entre os governos federal e estadual paulista, relacionando-a à dívida global do estado.

\section{A decisão de intervir}

Em 30 de dezembro de 1994, o Banco Central declarou a insolvência do Banespa e do Banerj, implementando o Regime de Administração Especial Temporária (RAET), a partir do qual o BACEN assumiu o controle administrativo de ambos ${ }^{10}$ Enquanto a intervenção foi baseada na incapacidade do Banespa e do Banerj para saldar suas obrigações financeiras junto ao Banco Central, o timing da decisão foi primordialmente político. O governo federal defrontou-se com uma série de oportunidades de intervenção entre o período do fim do mandato do governador Luís António Fleury e o início do mandato do governador Mário Covas, quando os custos políticos da intervenção eram menores do que o normal. Por um lado, o governo federal beneficiou-se da "lua-de-mel" eleitoral, com a eleição do presidente Fernando Henrique Cardoes; por outro lado, os custos políticos a serem enfrentados pelo governo Covas, recentemente eleito, foram minorados na medida em que foram considerados fait accompli. Enquanto a oposição de Covas para uma eventual privatização do Banespa será discutida mais adiante, um rápido sumário da decisão do Banco Central de intervir demonstra a extensão da dimensão iminentemente política do processo de tomada de decisão da autoridade monetária e também a prudência da oposição subnacional, caracterizando a incompletude da idéia corrente da "recentralização", a qual pretendemos desenvolver.

De acordo com o Decreto Lei 2.321, o Banco Central é habilitado a declarar o RAET, na medida em que qualquer instituição financeira não honre com as suas reservas bancárias. A intervenção do Banespa e do Banerj em 30 de dezembro de 1994, entretanto, não foi um mero reflexo, da parte do BACEN, de uma incapacidade de ambos em honrar suas obrigações financeiras. Quando um banco não tem fundos suficientes para fechar sua conta frente à autoridade monetária ao final de um dia de negócios, há duas opções: ou toma um empréstimo de curto prazo no mercado interbancário, ou lança mão do redesconto ${ }^{11}$, sofrendo penalidades do

\footnotetext{
10 A capacidade do BACEN para declarar o RAET às instituições públicas e privadas foi estabelecida através do decreto lei 2321, de 25/02/87.

11 O primeiro, conhecido como o Certificado de Depósito Interfinanceiro, ou Interbancário (CDI), consiste numa operação normal, a qual não requer qualquer garantia fornecida pela instituição financeira tomadora do empréstimo. O uso contínuo deste mercado, entretanto, muitas vezes, leva ao detrimento da credibilidade e assim eleva as taxas de juros envolvidas na transação. O redesconto, ou empréstimo de liquidez, por sua vez, é uma forma de "socorro" garantida pela Banco Central, pela qual este empresta
} 
BACEN. No segundo semestre de 1994, o Banespa foi continuamente forçado a usar o CDI para fechar suas contas ${ }^{12}$, sendo que esta opção de liquidez foi cortada em meados de setembro, quando uma grande instituição financeira privada se recusou a financiar a dívida mobiliária do banco, reduzindo assim severamente a credibilidade do Banespa junto ao Mercado Interbancário ${ }^{13}$. Para evitar as penalidades financeiras do redesconto, o Banco Central estendeu o financiamento do Banespa em CDI através do Banco do Brasil; uma operação conduzida pela GEROF (Gerência de Operações Financeiras do Banco do Brasil S/A). Desta forma, o governo federal, através do Banco do Brasil, manteve o Banespa solvente por um período de três meses e meio antes do RAET ser declarado.

No dia 29 de dezembro do mesmo ano, a GEROF concedeu somente R \$ 400 milhões para o Banespa através do CDI, uma pequena soma considerando que o banco havia recebido um montante superior a $\mathrm{R} \$ 3,5$ bilhões em outras ocasiões. Sendo incapaz de obter fundos através do CDI, o Banespa solicitou um empréstimo de liquidez de R \$ 1,311 bilhões ao Banco Central, o qual recusou a solicitação, com base nas garantias inadequadas que o banco oferecia. Naquela noite, então, o Banco Central declarou o RAET do Banespa, devido à sua impossibilidade de dar garantias suficientes para o redesconto.

Enquanto a intervenção do Banespa não foi conduzida por bases econômicas arbitrárias, a data da sua intervenção aparentemente foi. Dado que o Banco do Brasil manteve o Banespa solvente por aproximadamente quatro meses através da GEROF, não houve razões puramente econômicas para presumir que esse auxílio financeiro ao Banespa seria interrompido no dia 29 de dezembro em diante. Entretanto, o governo federal teve uma boa razão política: reduzir os "espinhosos" custos políticos de intervenção nos dois maiores bancos comerciais estaduais do Brasil.

Ao contrário do RAET anterior, declarado pelo Banco Central sobre os bancos comerciais estaduais, em 1994 o governo federal claramente expressou o seu desejo em não devolvê-los para as mãos de seus controladores, após a reestruturação de suas dívidas. O presidente do Banco Central na época, Pérsio Arida, em várias ocasiões explicitou os objetivos do governo em privatizar o Banespa e o Banerj após as suas respectivas intervenções, conforme a condição sine qua non, idealizada pelo governo, de redução do setor bancário estatal para a garantia de sucesso do

os fundos necessários ao banco que não fechou sua conta diária e não consegue captá-los no CDI. Entretanto, neste caso, o Banco Central demanda garantias na forma de ativos financeiros. Com a mudança no Sistema Brasileiro de Pagamentos, a ser levada a cabo no ano de 2001, o problema da conta de Reserva Bancária não será conhecido apenas no final do dia, o que diminuirá o risco do BACEN.

12 As dificuldades financeiras enfrentadas pelo Banespa em parte refletem o duro golpe representado pelo advento do Plano Real no sistema financeiro nacional, com o estancamento do processo inflacionário. Conforme já explicamos, houve um aumento do empréstimo compulsório recolhido pelo BACEN na ordem de $100 \%$ sobre os depósitos à vista e $30 \%$ sobre os depósitos à prazo. Este último atingiu especialmente o Banespa devido ao montante de $\mathrm{R} \$ 3,8$ bilhões de depósitos à prazo que o banco tinha naquele momento.

${ }^{13}$ Relatório da Comissão Parlamentar de Inquérito: Banespa; requerimento no 15 de 1995; p. 4. 
Plano Real ${ }^{14}$. Como as negociações prévias sobre bancos estaduais demonstraram, tais objetivos encontrariam indubitavelmente forte resistência política de governadores e de seus respectivos deputados estaduais.

A decisão de intervir em 30 de dezembro de 1994 teve o objetivo de minorar os custos políticos da intervenção federal nos bancos estaduais. Por um lado, intervir no último dia do mandato do governador Fleury foi uma estratégia do governo federal de minar a capacidade de reação do governo estadual à intervenção, oposição subnacional que, em larga medida, pode ser responsabilizada pelos problemas do banco. Por outro lado, o recém-empossado governador Mário Covas seria mais receptivo à intervenção não somente porque a ele foi apresentado um fato já consumado (assim poupando-se de qualquer responsabilidade política), mas também porque o Banco Central poderia incorrer em medidas de alto custo político, como reduzir o número de agências dos bancos e demitir funcionários ${ }^{15}$. Enquanto o governador Covas prontamente concordou e mesmo encorajou ${ }^{16}$ o Banco Central a implementar as medidas de austeridade para salvar o banco do ônus político de fazê-lo, o ponto principal da controvérsia foi se o Banespa permaneceria nas mãos do Estado de São Paulo.

Independente de conflitos futuros, o episódio da intervenção do Banespa e do Banerj demonstra um importante ponto: o timing da intervenção foi primordialmente político, com o objetivo de reduzir a oposição política para uma eventual privatização do banco. "Reduzir a oposição política" significa dois tipos de ação estratégica distintos, ambos levando em conta a dimensão temporal. Primeiro, a intervenção no último dia do governo Fleury implicou em tornar inviável qualquer tipo de retaliação por parte do governador, na medida em que se tratava de um governo cujas possibilidades de ação efetiva no campo político, inclusive tendo em vista as bancadas estaduais no Congresso, já se haviam esgotado. Neste caso, podese dizer que a redução de oposição política à privatização do Banespa se dá porque o outro ator - o governador Fleury — já não tinha recursos de poder à mão, não tinha condições concretas de se opor à intervenção.

\footnotetext{
14 Jornal do Brasil, 01/01/1995 e Gazeta Mercantil, 01/02/1995.

${ }^{15}$ Estes últimos foram abordados claramente em declarações de membros da equipe de Covas após a intervenção, irritados pelo fato de que o Banco Central tenha levado um longo tempo para decretar a intervenção do Banespa (Gazeta Mercantil, 01/02/1995). De acordo com entrevista do deputado Rui Falcão (PT-SP), à época, líder de sua bancada, parte do custo político advinha do fato de vários prefeitos se oporem ostensivamente à idéia, uma vez que "cada município que perde uma agência do Banespa, perde empregos, perde circulação de moeda". Entrevista concedida a Christopher Garman e Cristiane Kerches em 30/06/98.
}

\footnotetext{
${ }^{16} \mathrm{~A}$ administração Covas indicou, somente dois dias após a intervenção, que não se oporia às medidas de austeridade promovidas pelo BACEN sobre o Banespa, além da assessoria federal na administração do banco, mesmo admitindo que tais medidas poupariam Covas dos custos políticos de tomar tais medidas (Gazeta Mercantil, 01102/95, "Covas diz que o governo paulista não vai opor-se a medidas de saneamento”). A administração Covas, contudo, produziu várias críticas durante o ano de 1995 dirigidas à ação tardia do BACEN em tomar medidas de austeridade, como o enxugamento de empregos no sistema bancário estadual e o fechamento de agências.
} 
Por outro lado, a intervenção na véspera da posse do governador Mário Covas significou agir antes que este pudesse esboçar qualquer tipo de reação e, ao mesmo tempo, reduziria sua capacidade de oposição, na medida em que o desonerava das tarefas referentes ao saneamento do Banespa, que ficaram a cargo do Executivo federal (através da ação do Banco Central). Deste modo, a redução da oposição se dá porque o novo ator com o qual se interage é desonerado dos custos da medida, não tendo por que se opor de forma mais contundente.

\section{Primeira rodada: o protocolo de intenções e a sua tramitação no Senado e na Assembléia Legislativa.}

A despeito do cuidado do Banco Central em reduzir os custos políticos da intervenção, o governo federal encontrou uma dura resistência em sua empreitada de privatizar o Banespa ${ }^{17}$. A preferência do governo federal por uma eventual privatização do banco foi explicitada pelo Presidente do BACEN, Pérsio Arida, e menos veementemente pelo Presidente Fernando Henrique Cardoes ${ }^{18}$. A equipe econômica do governo diagnosticou a pressão monetária exercida pelos bancos estaduais como um fator incompatível com o esforço estabilizador do Plano Real. Em grande medida, esse diagnóstico levou ao encaminhamento de uma solução crítica para o Banespa, dada a sua importância relativa no sistema bancário estadual. Como o presidente do BACEN descobriria logo, uma oposição política para um acordo relativamente rápido em torno da privatização do banco provou-se possível $^{19}$.

O Banco Central encontrou oposição para uma ,eventual privatização do Banespa em um front multifacetado consistindo de governadores, deputados federais e estaduais, representantes do setor privado, e obviamente, representantes das instituições públicas financeiras de São Paulo. A oposição à privatização do Banespa foi quase unânime entre os deputados federais da bancada paulista na Câmara, completamente independente de disposições ideológicas ${ }^{20}$. Duas comissões supra-

\footnotetext{
${ }^{17}$ A decisão de Covas de se opôr a uma eventual privatização do Banespa contrastou com a decisão do governador Marcelo Alencar (PSDB) de privatizar o Banerj. Para uma análise parcial das diferentes decisões tomadas por Covas e Alencar, ver Leslie Eliot Armijo e Prem Shankar Jah, 1997.

18 Jornal do Brasil, 01101/95.

${ }^{19}$ No momento da intervenção, Pérsio Arida veio a declarar seu desejo de um máximo de 60 dias para negociar o futuro de ambos os bancos - Banespa e Banerj - com a percepção ex post da real conjuntura, uma tarefa virtualmente impossível (Gazeta Mercantil, 01/02/95).

${ }^{20} \mathrm{O}$ bloco opositor à privatização do Banespa estendeu-se também entre os deputados tradicionalmente de inclinação privatista. Ricardo Izar (PPR-SP), por exemplo, conhecido por sua ação de defesa das privatizações, declarou: "São Paulo não deve e não pode prescindir do Banespa. O Banespa em si é uma instituição irreversível. Não é só um banco. Hoje o Banespa são diversas instituições - corretoras de seguros, clube, fundo, é tudo. Tem tanta gente dependendo dele! O que aconteceu com o Banespa foi um esporádico acidente de má administração. Sou um grande defensor das privatizações, mas não no caso do Banespa. Não tem razão" (Gazeta Mercantil, 08/03/95).
} 
partidárias foram criadas na Câmara dos Deputados em oposição à privatização do Banespa ${ }^{21}$, com a oposição à privatização extrapolando a bancada paulista. Nelson Marquezelli (PTB-SP), líder da bancada ruralista na Câmara, por exemplo, declarou que toda a bancada ruralista, ao todo 120 deputados, faria oposição a uma eventual privatização ${ }^{22}$.

A ação legislativa substantiva na Câmara dos Deputados, entretanto, não representou sérias ameaças à capacidade legal formal do Banco Central de liquidar o banco ou federalizar a instituição. A ameaça real da bancada paulista e dos deputados de oposição à privatização do Banespa vinha de uma obstrução legislativa potencial para futuros itens legislativos favorecidos e introduzidos pelo executivo federal. O deputado Maluly Neto (PFL-SP), por exemplo, anunciou: "Se o governo federal não negociar com a bancada paulista o destino do Banespa, nós vamos rechaçar o que o Executivo mandar para o Legislativo" 23 .

Com uma dura oposição na Câmara dos Deputados e do governador Mário Covas, o Banco Central logo recuou de suas exigências iniciais de privatizar o Banespa. As negociações que ocorreram durante todo o ano de 1995, entretanto, foram focadas entre o BACEN e a administração Covas na perspectiva de uma potencial barganha, a partir da qual o banco seria mantido nas mãos do governo do estado. Enquanto poucas propostas diferentes foram consideradas, as negociações finalmente foram abertas quando o governador Covas concordou em pagar metade da dívida do governo do estado devida ao Banespa, um montante de $\mathrm{R} \$ 14$ bilhões, através da venda à iniciativa privada dos aeroportos de Cumbica, Congonhas, Viracopos e a FEPASA. A segunda metade da dívida seria financiada através de um empréstimo do Tesouro Nacional, a taxas de juros reais subsidiadas de $6 \%$ ao ano.

Com o protocolo de intenções para tal acordo assinado pelos governos estadual e federal em janeiro de 1996 (um ano após a intervenção), o próximo passo para o governador era aprovar o acordo na Assembléia Estadual e no Senado Federal ${ }^{24}$. Enquanto os deputados do PMDB, do PFL e do PT ameaçavam obstruir a

${ }^{21}$ A primeira comissão - Comissão Parlamentar Suprapartidária Contra a Liquidação Extrajudicial do Banespa -, liderada pelo deputado Hélio Rosas (PMDB-SP) consistiu em toda a bancada paulista (70 deputados) e demandou vários encontros com o presidente do BACEN. A segunda comissão foi formada por deputados do PT, PC do B e PSB, que fez uma defesa das bancos públicos independente do caso Banespa (Folha de São Paulo, 18/02/95 e DCI, 23/02/95).

${ }^{22}$ Folha de São Paulo, 18/02/95. A oposição à privatização do Banespa da bancada ruralista foi compreensível, considerando o fato de que de acordo com um estudo do DIEESE, $85,5 \%$ de todas as operações de crédito com o setor rural são conduzidas pelos bancos comerciais estatais e $96 \%$ das operações de crédito rural em São Paulo são conduzidos pelo Banespa. A oposição mais forte do setor privado à privatização do Banespa foi feita pela Federação Agrícola do Estado de São Paulo, capitaneada por Fábio Meirelles. Gazeta Mercantil, 08/03/95.

${ }^{23}$ Gazeta Mercantil, 08/03/95. Tais pronunciamentos foram dados pelo líder do PMDB na Câmara, Michel Temer (PMDB-SP), 22/08/95.

24 O Senado é responsável por estabelecer os limites da dívida e operações para governos estaduais e municipais. 
passagem do protocolo ao introduzir um número grande de emendas, que desvirtuariam a natureza do documento - e assim demandando uma nova rodada de negociações - , o governo foi bem sucedido ao conseguir passar o protocolo na Assembléia Estadual em somente 16 dias.

A tarefa mais difícil para o governador ainda estava por vir: passar o protocolo pelo Senado. Logo no início das negociações, o presidente do Senado na época, senador José Sarney (PMDB-AP), questionou se o estado de São Paulo tinha recebido tratamento favorável do governo federal. $\mathrm{Na}$ renegociação da dívida do estado junto ao Banespa, São Paulo também encontraria uma solução para a questão das dívidas das empresas estatais ${ }^{25}$. Imediatamente, na seqüência do trâmite do protocolo no Senado, uma CPI proposta para a investigação do sistema financeiro nacional, com foco nas ações intervencionistas do Banco Central no caso Banespa e Banerj, ameaçou obstruir a votação no Senado de um empréstimo de R \$ 7,5 bilhões ao estado de São Paulo ${ }^{26}$.

A CPI do sistema financeiro nacional, entretanto, tinha uma chance muito pequena de ser efetiva em suas ações investigativas ${ }^{27}$. A motivação real para tais

propostas obstrucionistas potenciais veio do descontentamento de senadores dos estados do Norte, Nordeste e Centro Oeste, que reivindicavam tratamento igualitário para todos os estados ${ }^{28}$. Contudo, as negociações no Senado somente progrediram quando o representante da Comissão de Assuntos Econômicos do Senado (CAE), Gilberto Miranda (PMDB-AM), apoiou uma proposta do senador Ney Suassuna (PMDB-PB) para garantir tratamento financeiro similar para todos os estados ${ }^{29}$. O líder do governo no Senado, Élcio Álvares (PFL-ES), com o aval do presidente Fernando Henrique, então garantiu que o governo federal proveria crédito similar para todos os bancos comerciais estaduais com problemas financeiros, garantia que forneceu a espinha dorsal do programa de reestruturação dos bancos estaduais, criado nos três meses seguintes à votação do caso Banespa.

Em suma, o acordo com o governo federal para a aceitação do protocolo de intenções, segundo o qual o Banespa seria mantido nas mãos do governo do estado de São Paulo, mostrou até que ponto as pressões políticas subnacionais foram capazes de resistir com sucesso às primeiras intenções privatizantes do Banco Central cóm relação ao Banespa. A despeito do cuidado tomado pelo governo federal para minorar os custos da intervenção e do diagnóstico da equipe econômica do presidente Fernando Henrique Cardoes, da necessidade de privatizar o banco em nome

\footnotetext{
${ }^{25}$ O Estado de São Paulo, 23/02196.

${ }^{26}$ A proposta da CPI sobre o sistema financeiro foi introduzida por Antônio Carlos Valadares (PSB-SE), com o apoio do senador José Sarney (O Estado de São Paulo, 06/03/96).

${ }^{27}$ Em grande medida porque provocaria embaraços políticos a muitos senadores que faziam transações financeiras suspeitas e poderiam ser revelados com a quebra do sigilo bancário.

${ }^{28} \mathrm{O}$ senador Antônio Carlos Magalhães (PFL-BA) corroborou essa intenção com o seu apoio à criação da CPI (O Estado de São Paulo, 06/03/96).
}

${ }^{29}$ O Estado de São Paulo, 16/04/96. 
da sobrevida do plano de estabilização, a força dos interesses políticos de São Paulo prevaleceu, ao menos numa perspectiva de curto prazo.

\section{Segunda rodada: o abandono do protocolo e a inserção do Banespa na negociação da dívida do estado de São Paulo.}

Apesar da aprovação no Senado de um empréstimo de R\$ 7,5 bilhões ao estado de São Paulo, o governador Mário Covas abandonou o protocolo de intenções assinado em janeiro de 1996, logo após a votação no Senado. Tendo ocorrido aproximadamente cinco meses, desde o acordo entre o estado de São Paulo e o governo federal, a dívida de São Paulo junto ao Banespa cresceu R 3 bilhões somente em virtude do montante acumulado de juros não pagos, e o governador Mário Covas declarou que São Paulo não retomaria o controle sobre o Banespa sem uma rolagem da dívida, subsidiada. Como o governo federal e o governo de São Paulo foram incapazes de concordar sobre o total a ser pago de juros acumulados, as negociações foram paralisadas.

Três semanas após a declaração do governador Covas de que São Paulo não retomaria o controle sobre o Banespa, uma possível solução para a paralisia nas negociações começava a emergir. O Secretário executivo do Ministério da Fazenda, Pedro Parente, sinalizou que o governo já estava pronto para criar um programa nos moldes do PROER para os bancos comerciais estaduais, o qual também incluiria uma solução para os $\mathrm{R} \$ 3,5$ bilhões em juros acumulados não pagos. Como abordamos anteriormente, o programa implementado pelo governo federal através da MP 1.514 proporcionou ao governo do estado duas opções básicas. O governo federal podia prover financiamento para o valor total da dívida junto aos bancos comerciais, demandando como contrapartida eventuais privatizações ou transformação da instituição em agência de fomento, ou o estado podia manter a posse do banco comercial e teria de pagar imediatamente $50 \%$ da dívida com recursos próprios. Além disso, existe uma cláusula específica na MP para o caso Banespa; os $\mathrm{R}$ \$ 3,5 bilhões em juros acumulados seriam incluídos nas condições acima.

O presidente Fernando Henrique Cardoes manteve a promessa feita aos senadores e governadores durante as negociações no Senado, concernente à petição de São Paulo para o financiamento do protocolo original. O Banco Central proporcionou um pacote de assistência geral para os governos estaduais, atendendo bancos que necessitaram de socorro financeiro. Os termos específicos do financiamento arremedaram o protocolo de intenções assinado por São Paulo - metade da dívida seria paga com os próprios recursos do estado, e a outra metade financiada em 30 anos com empréstimos subsidiados à taxa de juros de $6 \%$ a.a.

A despeito do pacote de socorro ser similar ao oferecido aos outros estados, o governador Mário Covas recusou a alternativa de manter o controle do Banespa nas mãos do estado, pois a dívida presente do governo junto ao Banespa havia aumentado de $\mathbf{R} \mathbf{8} 8$ bilhões para o surpreendente montante de $\mathbf{R} \mathbf{\$} 20$ bilhões, somente devido ao estoque de juros não pagos acumulados. A dívida do estado junto ao Banespa, entretanto, foi somente uma parte do déficit paulista do setor público 
que totalizava R\$ 56 bilhões (em agosto de 1996), em constante aumento devido às altas taxas de juros pagas pelos Títulos da Dívida Pública Estadual. Para uma solução da dívida do Banespa, entretanto, o estado ainda seria levado a uma situação de extrema precariedade fiscal, a qual restringiria a capacidade do governador de alavancar investimentos. O governador Mário Covas e os representantes do Ministério da Fazenda tomaram uma decisão estratégica: negociar a privatização do Banespa em um contexto mais amplo de renegociação da dívida, que levaria a uma solução para toda a dívida do setor público do estado de São Paulo.

As partes envolvidas finalmente chegaram a um acordo no final de novembro de $1996 .{ }^{30}$ Como nos casos dos outros estados que renegociaram suas dívidas com o governo federal, este concordou em financiar $80 \%$ da dívida de São Paulo e deixar os outros $20 \%$ sob a responsabilidade do estado. Entretanto, São Paulo recebeu duas concessões do governo federal. Em vez de pagar $20 \%$ à vista, São Paulo só teve de pagar imediatamente R \$ 2,2 bilhões, enquanto o restante dos $20 \%$ seriam pagos em prestações. Para honrar estas obrigações financeiras, o estado ini-ciou o processo de privatização de algumas das suas empresas estatais, como a Companhia Energética de São Paulo (CESP), a Companhia Paulista de Força e Luz (CPFL) e a Eletropaulo.

Com o acordo firmado com o governo federal sobre o caso Banespa e a dívida do estado, o governador buscou aprovar o acordo na Assembléia Estadual e, surpreendentemente, encontrou pouca resistência dos deputados estaduais. Tal resultado pode parecer surpreendente, considerando os vários protestos dos deputados federais e estaduais contra o desejo do governo federal em privatizar o Banespa. A concordância da Assembléia Legislativa com o acordo pode ser entendida por dois fatores centrais. Primeiro, a necessidade veemente de encontrar uma solução para a grave crise fiscal do estado de São Paulo foi também relevante para os deputados estaduais "reverem sua posição". Sem um reescalonamento da dívida do estado, não somente o governador estaria incapacitado de conduzir novos investimentos, mas os deputados estaduais também enfrentariam uma dura tarefa para atender às demandas de suas bases eleitorais. Em segundo lugar, os deputados estaduais começaram a vislumbrar na Nossa Caixa uma potencial alternativa ao Banespa. Sob nova administração, a NC saiu do redesconto em menos de seis meses e melhorou todos os seus indicadores, assim constituindo-se como um substituto viável do Banespa.

Com custos maiores não resolvidos, a crise fiscal do estado e os decrescentes custos políticos para a privatização, a Assembléia Estadual aprovou a transferência do controle do Banespa para as mãos do governo federal. Na realidade, houve uma mudança do status quo ao longo do período que fez com que se alterasse o leque de preferências dos parlamentares, assim como do próprio governador Mário Covas. Se antes privatizar significava abrir mão de um importante recurso de poder

\footnotetext{
${ }^{30}$ As pressões para fechar um acordo antes do final de 1996 foram especialmente grandes, porque o RAET estava terminando no Banespa, fazendo com que fosse tomada alguma medida legal capitaneada pelo Banco Central: a liquidação ou a federalização do banco.
} 
político e econômico do estado na arena federativa, com a piora das contas públicas, privatizar passou a significar: primeiro, a não responsabilização política pelo pesado ónus do ajuste fiscal e, em segundo lugar, não necessariamente a ausência de um banco estatal, dado o vislumbramento, por parte dos atores políticos estratégicos, da Nossa Caixa como alternativa institucional ao Banespa, a despeito da vigência e da necessidade do efetivo cumprimento das regras de solvência dos bancos, no período pós-Plano Real.

Em suma, apesar de um visível enxugamento da instituição (vide Tabela 5), que reflete a maior autonomia de ação do BACEN junto aos bancos públicos, o episódio envolvendo a intervenção federal no Banespa fornece algumas respostas para as questões enunciadas no início deste artigo. O caso demonstra que a tentativa federal de privatizar os bancos estaduais não se enquadra em uma prematura idéia da "recentralização", como também não indica que os governadores têm sido capazes de conduzir politics as usual, como veremos a seguir.

Tabela 5: Mudanças no Banespa pós-intervenção

\begin{tabular}{lcc}
\hline \multicolumn{1}{c}{ Indicador } & dez/94 & jun/00 \\
\hline Número de Empregados & $33,8 \mathrm{mil}$ & $21 \mathrm{mil}$ \\
Agências & 612 & 578 \\
Captação de Recursos & $8,5 \mathrm{bi}$ & $11,1 \mathrm{bi}$ \\
Base de Clientes & 3 milhões & 3 milhões \\
\hline
\end{tabular}

Fonte: Banespa (Demonstrações Financeiras)

Ademais, o longo processo de privatização do Banespa, que foi postergado por diversas vezes em função de disputas jurídicas, demonstrou também que um outro importante ator com poder de veto, o Poder Judiciário - e o próprio Ministério Público - , deve ser objeto de análise mais acurada, para que se tenha uma visão completa dos fatos, uma vez que aqui privilegiamos somente o corte da análise federativa.

\section{CONSIDERAÇÕES FINAIS}

Conforme citamos na introdução deste artigo, há uma interpretação corrente (principalmente na imprensa e em análises de cunho estritamente economicista) de que está acontecendo um processo de recentralização de poder político nas mãos do Executivo Federal, em relação aos governos subnacionais, após a implementação do Plano Real. Segundo essa corrente, tratar-se-ia de um processo impositivo por parte do governo federal, necessário para a própria sobrevida do Plano, sendo unilateralmente imposto aos estados que, a partir de então, teriam suas posições relativas de poder, no plano federativo, enfraquecidas. É como se fosse um proces- 
so capitaneado essencialmente pela lógica da racionalidade econômica, trazendo em seu bojo um subproduto, que é o cunho político do mesmo.

No entanto, nossa análise questionou essa visão, ao demonstrar, lançando mão do caso Banespa, que as evidências do processo denotam variáveis políticas muito importantes, que também são elementos causais de tal processo. Isso, de certa forma, viria requalificar essa idéia de "recentralização", na medida em que considera a miríade de fatores que acabam por explicar melhor o que se supunha ter uma única lógica: a transformação do sistema financeiro, mormente no que tange aos bancos estaduais. Acabamos por concluir que, enquanto a autonomia financeira dos governos estaduais tem sido significativamente restringida com a eliminação de suas respectivas instituições financeiras, o PROES reflete uma série de negociações, não somente envolvendo a questão dos bancos, mas também a questão da dívida dos estados junto a estes. Dado que essas negociações foram "casadas" com as negociações das dívidas totais dos estados, o programa citado foi criado como um meio para mitigar tanto a crise fiscal dos governos estaduais, como para sustentar, num prazo mais longo, o plano econômico que se gestava, na medida em que resolvia o crónico problema dos bancos públicos estaduais. Visto que, além das negociações políticas que ficaram explícitas no estudo de caso do Banespa, também houve negociações congêneres por uma paridade de tratamento vis-à-vis aos demais estados, na verdade queremos crer que a crise fiscal representou, deste modo, a criação do fato da barganha no jogo político que envolveu a solução do caso dos bancos estaduais insolventes, no qual se inseriram governadores, congressistas e governo federal.

Tratou-se então de um jogo multifacetado, no qual todos os lados cederam, muito mais do que se imagina correntemente.

Enquanto os governos subnacionais perderam um mecanismo extremamente eficaz de auto-financiamento, o governo federal acabou por conseguir recentralizar a autoridade monetária nas mãos do Banco Central, internalizando os ónus do ajuste, ao menos no curto prazo.

Na opinião dos gestores do Banco Central, a partir do PROES, não haverá mais tratamento privilegiado para bancos estaduais, sendo que para estes “ ... não existe banco estadual ou federal, existe banco" ${ }^{1}$. As regras do sistema bancário, no período posterior ao Plano Real, incrementadas pela necessidade de atendimento aos parâmetros internacionais, devem valer para todos os bancos, sejam eles privados ou públicos. Como revelou o à época presidente do Banespa e funcionário do Banco Central, João Magro, ao menos "da cintura para cima do balanço, os bancos públicos estaduais tem de ser iguais aos outros ( bancos )". ${ }^{32}$

Acreditamos, calcados no exemplo do próprio Banespa, que há substrato técnico suficiente para avalizar a crença de que as mudanças têm um caráter permanente. No entanto, os próprios fatos políticos mencionados neste artigo acabam

\footnotetext{
${ }^{31}$ Paolo Zaghen, entrevista citada.

32 Entrevista em 08.05.98.
} 
por gestar dúvidas quanto à aplicabilidade exclusiva da racionalidade técnica num contexto democrático, uma vez que o tom das soluções se dá invariavelmente na arena política, modulando os critérios técnicos.

\section{REFERÊNCIAS BIBLIOGRÁFICAS}

ABRUCIO, Fernando Luiz (1998) Os Barões da Federação: os Governadores e a Redemocratização Brasileira. São Paulo: Hucitec.

ABRUCIO, Fernando Luiz e SAMUELS, David J. (1997) "The New Politics of the Governors: Subnational Politics and the Brazilian Transition to Democracy". São Paulo: paper prepared for IPSA (mimeo). ARMIJO, Leslie E. (1988) The Political Economy of Brazilian Central Banking-1965 to 1987. Berkeley, CA: University of California — Department of Political Science, julho.

ARMIJO, Leslie E. e JAH, Prem S. (1997) "Center-State Relations in India and Brazil: Privatization of Electricity and Banking”, Revista de Economia Política, vol. 17, nº 3 (67), julho.

BANCO CENTRAL DO BRASIL (Gustavo Loyola). (1993) "Bancos Públicos Estaduais — Origens da 'Questão BE's' e Perspectivas do Setor”, Série Pronunciamentos.

BARROS, José R. M. e ALMEIDA JR., Mansueto Facundo (1997) “Análise do Ajuste do Sistema Financeiro no Brasil”, Política Comparada, vol. 1, n 12. Brasília.

BARROS, José R. M, LOYOLA, Gustavo J. L. e BOGDANSKI, Joel. (1998) "Reestruturação do Setor Financeiro". Paper do Ministério da Fazenda, janeiro.

BATISTA JR., Paulo Nogueira. (1996) O Plano Real à Luz da Experiência Mexicana e Argentina. São Paulo: IEA/USP, setembro.

BIER, Amaury, PAULANI, Leda M. e MESSEMBERG, Roberto (1987) O Heterodoxo e o Pós-Moderno: o Cruzado em Conflito. Rio de Janeiro: Paz e Terra.

CAMPOS, Roberto de O. (1994) A Lanterna na Popa. Rio de Janeiro: Topbooks.

CUKIERMAN, Alex, WEBB, Steven B. e NEYAPTI, Bilin (1994) Measuring Central Bank Independence and Its Effect on Policy Outcomes. San Francisco, CA: ICS Press.

DAHL, Robert A. (1982) Dilemmas of Pluralist Democracy-Autonomy vs. Control. New Haven and London: Yale University Press.

FORTUNA, Eduardo (1995) Mercado Financeiro: Produtos e Serviços. Rio de Janeiro: Qualitymark. GOUREVITCH, Peter A. (1993) "Democracy and Economic Policy: Elective Affinities and Circumstantial Conjunctures", World Development, vol. 21, $\mathrm{n}^{\circ} 8$.

IBGE e ANDIMA “Sistema Financeiro: Uma análise a partir das Contas Nacionais 1990 -1995". KANDIR, Antonio (1994) Brasil Real: A Construção da Cidadania, da Moeda e do Desenvolvimento. São Paulo: Klick.

KEOHANE, Robert O. e MILNER, Helen V. (1996) Internationalization and Domestic Politics. Cambridge: Cambridge University Press.

LOPES, Francisco (1989) O Desafio da Hiperinflação. Rio de Janeiro: Campus, capítulos 5 e 6 . MALLOY, James M. (1993) "Política Econômica e o Problema da Governabilidade Democrática nos Andes Centrais”, in Sola, Lourdes, org. (199 3) Estado, Mercado e Democracia. São Paulo: Paz e Terra.

MARTONE, Celso (1994) “A Reestruturação da Política Monetária”, in Reis Velloso, J. P., org. (1994) Inflação, Moeda e Desindexação. São Paulo: Nobel.

MAXFIELD, Sylvia (1995) Gatekeepers of Growth: The International Political Economy of Central Banking in Developing Countries. Yale University, Department of Political Science (no prelo).

PAES, Julieda Puig Pereira.(1996) “Bancos Estaduais, ‘Criação’ de Moeda e Ciclo Político”. São Paulo: FGV, Dissertação de Mestrado.

BRESSER-PEREIRA, Luiz C. (1996) Crise Econômica e Reforma do Estado no Brasil. São Paulo: Editora 34 .

PRZEWORSKI, Adam (1995) Estado e Economia no Capitalismo. Rio de Janeiro: Relume Dumará. 
PRZEWORSKI, Adam (1996) "Reforma do Estado — Estabilidade Política e Intervenção Econômica", in Revista Brasileira de Ciência Sociais, $\mathrm{n}^{\circ}$ 32, ano 11, outubro.

RESENDE, André Lara (1992) "O Conselho da Moeda: Um Órgão Emissor Independente" in Revista de Economia Política, vol. 12, $\mathrm{n}^{\circ} 4$ (48), outubro.

SADDI, Jairo. (1997) O Poder e o Cofre - Repensando o Banco Central. São Paulo: Textonovo. SOLA, Lourdes (1995) “Estado, Regime Fiscal e Ordem Monetária: Qual Estado?”, in Lições da Década de 80. São Paulo: Edusp.

SOLA, Lourdes e KUGELMAS, Eduardo (1996) On Statecraft, Economic Liberalization and Democratization. São Paulo (mimeo).

SOLA, Lourdes, GARMAN, Christopher e MARQUES, Moisés (1998) "Central Banking, Democratic Governance and Political Authority: The Case of Brazil in a Comparative Perspective”, Revista de Economia Política, vol.18, ${ }^{\circ} 2(70)$, abril.

THE ECONOMIST (1992) "Fear of Finance", Setembro.

THE WORLD BANK (1990) "Brazil -The dilemma of Brazil's state banking system: an analysis and suggestions for reform”, Report n ${ }^{\circ} 8247-B R$, vol. I, February. 